\title{
Hemodynamic monitoring in the critically ill patient - current status and perspective
}

\author{
Samir G. Sakka* \\ Department of Anesthesiology and Operative Intensive Care Medicine, Medical Center Cologne Merheim, University \\ Witten/Herdecke, Cologne, Germany
}

In the critically ill patient, early and effective hemodynamic management including fluid therapy and administration of vasoactive drugs to maintain vital organ perfusion and oxygen delivery is mandatory. Understanding the different approaches in the management of critically ill patients during the resuscitation and further management is essential to initiate adequate context- and time-specific interventions. Treatment of hemodynamic variables to achieve a balance between organ oxygen delivery and consumption is the cornerstone. In general, cardiac output is considered a major determinant of oxygen supply and thus its monitoring is regarded helpful. However, indicators of oxygen requirements are equally necessary to assess adequacy of oxygen supply. Currently, more and more less or even totally non-invasive monitoring systems have been developed and clinically introduced, but require validation in this particular patient population. Cardiac output monitors and surrogates of organ oxygenation only enable to adequately guide management, as patient's outcome is determined by acquisition and interpretation of accurate data, and finally suitable management decisions. This mini-review presents the currently available techniques in the field of hemodynamic monitoring in critically ill patients and briefly summarizes their advantages and limitations.

Department of Anesthesiology and Operative Intensive Care Medicine,

Medical Center Cologne Merheim,

University of Witten/Herdecke,

Ostmerheimerstr. 200, Cologne

D-51109, Germany

sakkas@kliniken-koeln.de

Specialty section:

This article was submitted to Intensive Care Medicine and Anesthesiology,

a section of the journal

Frontiers in Medicine

Received: 14 April 2015

Accepted: 26 June 2015

Published: 03 August 2015

Citation:

Sakka SG (2015) Hemodynamic monitoring in the critically ill patient - current status and perspective.

Front. Med. 2:44.

doi: 10.3389/fmed.2015.00044

\section{Keywords: hemodynamics, monitoring, intraoperative, cardiac output, fluid therapy, catecholamines}

Since its introduction in the early 1970s the pulmonary artery catheter (PAC) was widely used and regarded as the "holy grail" in hemodynamic monitoring (1). This device, for the first time, allowed to measure extended hemodynamic variables, particularly cardiac output, cardiac filling pressures, and global oxygen transport, in the critically ill patient at the bedside. However, in 1996 when Connors et al. (2) reported in an observational study based on a matched-pair analysis that the use of a PAC was associated with an increased mortality and increased utilization of resources, even a moratorium for the PAC was called for by some authors. Over the following years, several large randomized controlled trials could not confirm these findings, however, they failed to demonstrate improved outcome in patients monitored with the PAC (3-6). Thus, up to date no damage but also no benefit on outcome by using a PAC has been documented. Consequently, a decline in PAC use over the following years developed $(7,8)$. Although potentially life-threatening complications during the catheter placement (e.g., cardiac arrhythmias and mechanical complications) are well described, data showed that negative impact on outcome is based on the period after the initial phase suggesting that correct measurement of variables and decisions made are more critical. Nevertheless, the PAC may still provide important information especially in patients with pulmonary arterial hypertension and right ventricular failure, however, there is consensus that the PAC should not be routinely used as the primary means of advanced monitoring (9). 
In general, no specific monitoring device has been found to reduce mortality in critically ill patients (10), which is not surprising as the conclusions drawn from the hemodynamic variables obtained and the treatment induced are finally determining. This statement is confirmed insofar, as there is a convincing body of evidence that goal-directed optimization of advanced hemodynamic variables reflecting global blood flow improves patients' outcome $(11,12)$.

During the time, when the PAC came under intense debate, more and more alternatives and especially less-invasive techniques were developed and evaluated in experimental and clinical studies. Besides transpulmonary indicator (e.g., thermal, lithium), dilution techniques, less-invasive technologies like esophageal Doppler and uncalibrated pulse contour analysis (based on a peripheral arterial signal) were introduced. Furthermore, as a logical step, several manufacturers have promoted and introduced totally non-invasive devices for advanced hemodynamic monitoring: e.g., thoracic bioimpedance, bioreactance, and ultrasound techniques. Although described first in the early 1990s, non-invasive systems for assessment of radial artery pressure curves based on the volume clamp method according to the Peñaz principle and applanation tonometry are currently intensively studied in critically ill patients.

In general, cardiac output as major and flow determinant variable of systemic oxygen delivery is often considered helpful in the management of critically ill patients. However, measurement of cardiac output per se is only of limited value as its interpretation (Frank-Starling relation) requires simultaneous information on cardiac preload and/or fluid responsiveness (as an a priori estimate of the impact of fluid loading on cardiac output). However, some but not all of the techniques listed below simultaneously provide information on cardiac output and cardiac preload or fluid responsiveness, respectively. Since not intended here and thus without claiming completeness, Table $\mathbf{1}$ provides an updated overview on the currently available systems (13).

Before providing an overview on these technologies, briefly discussing their strengths and weaknesses, an update on the status quo should be given. Today, as reported in a current survey from

TABLE 1 | Overview on various hemodynamic monitoring devices.

\begin{tabular}{|c|c|c|c|}
\hline Modality & Device & Equipment & Limitations \\
\hline Right heart catheterization & Pulmonary artery catheter & $\begin{array}{l}\text { Thermistor-tipped balloon catheter } \\
\text { Special types enabling continuous } \\
\text { monitoring of cardiac output and/or } \\
\text { mixed venous saturation, right } \\
\text { heart ejection or pacing modalities }\end{array}$ & $\begin{array}{l}\text { Invasiveness } \\
\text { Mechanical complications, arrhythmias, infections }\end{array}$ \\
\hline Central venous oxygen saturation & Central venous catheter & $\begin{array}{l}\text { Intermittent or continuous } \\
\text { measurement of } \mathrm{O}_{2} \text {-saturation }\end{array}$ & $\begin{array}{l}\text { Mechanical complications, arrhythmias, infections } \\
\text { Not equal to mixed venous } \mathrm{O}_{2} \text {-saturation }\end{array}$ \\
\hline \multicolumn{4}{|l|}{ Pulse pressure } \\
\hline Calibrated & $\begin{array}{l}\mathrm{PiCCO}^{\mathrm{R}} \\
\text { EV100/NolumeView }^{\mathrm{R}} \\
\text { LiDCO }^{\mathrm{R}}\end{array}$ & $\begin{array}{l}\text { Thermistor-tipped arterial catheter } \\
\text { Thermistor-tipped arterial catheter } \\
\text { Arterial catheter and lithium sensor }\end{array}$ & $\begin{array}{l}\text { Hematoma, vessel occlusion with ischemia, } \\
\text { embolism, infections } \\
\text { see above (cave: lithium levels) }\end{array}$ \\
\hline Uncalibrated & $\begin{array}{l}\text { FloTrac/Vigileo }^{\mathrm{R}} \\
\text { LiDCO Rapid }^{\mathrm{R}} \\
\text { PulsioFlex } \\
\text { PRAM } \text { (MostCare }^{\mathrm{R}} \text { ) }\end{array}$ & $\begin{array}{l}\text { Specific arterial kit } \\
\text { Specific arterial kit } \\
\text { Arterial catheter } \\
\text { Specific arterial kit }\end{array}$ & $\begin{array}{l}\text { Hematoma, vessel occlusion with ischemia, } \\
\text { embolism, infections }\end{array}$ \\
\hline Non-invasive & $\begin{array}{l}\text { Nexfin }^{R} \\
\text { CNAP }^{R} \\
\text { T-Line }\end{array}$ & $\begin{array}{l}\text { Finger pressure cuff } \\
\text { Finger pressure cuff, oscillometry } \\
\text { Radial applanation tonometry }\end{array}$ & $\begin{array}{l}\text { Local swelling, peripheral ischemia } \\
\text { Limited accuracy of measurement of absolute cardiac output }\end{array}$ \\
\hline
\end{tabular}

Ultrasound

Doppler

\begin{tabular}{|c|c|c|c|}
\hline Esophageal Doppler & CardioQ $^{\mathrm{R}}$ & Esophageal probe & Limited accuracy of measurement of absolute cardiac output \\
\hline Transthoracic Doppler & USCOM $^{R}$ & Transthoracic probe & \\
\hline Echocardiography & ClariTEE $^{\mathrm{R}}$ & Disposable monoplane echo probe & $\begin{array}{l}\text { Limited duration of placement, findings operator and } \\
\text { experience dependent }\end{array}$ \\
\hline
\end{tabular}

Fick principle

Dye dilution

\section{$\mathrm{NICO}^{\mathrm{R}} \quad$ Rebreathing loop}

DDG analyzer $^{R}$

$\mathrm{Bio}^{\mathrm{R}} \quad$ Specific electrodes

$\mathrm{NICOM}^{\mathrm{R}} \quad$ Specific electrodes

Aesculon $^{\mathrm{R}}$

Bioimpedance/-reactance

Thoracic bioimpedance

Thoracic bioreactance

Electrical velocimetry

Plethysmography

Plethysmogram variability

MASIMOR
Cutaneous sensor

Specific electrodes

No information on cardiac preload

Absolute measurement of cardiac output limited

Limited accuracy of measurement of absolute cardiac output

.


Switzerland, $56 \%$ of intensivists use transpulmonary thermodilution (1\% lithium dilution), 31\% a PAC, 9\% echocardiography, and $3 \%$ an uncalibrated pulse contour system, respectively (14). Notably, pulse pressure variation (PPV) and stroke volume variation (SVV) are mostly used in the Australia and New Zealand, while esophageal Doppler technology is preferred by anesthetists in the UK for guiding intraoperative fluid management (15).

In order to assess adequacy of oxygen delivery, central venous oxygen saturation $\left(\mathrm{ScvO}_{2}\right)$ as a measure of oxygen transport has been proposed since the trial by Rivers et al. in 2001 (16). However, the positive results of $\mathrm{ScvO}_{2}$-guided treatment on outcome in patients with sepsis as reported in this monocentric trial were recently challenged (17). From physiology, central and mixed venous oxygen saturation cannot be equal, however, the first as obtained in the V. cava superior can be obtained less invasively and is commonly used as a surrogate for the match/mismatch between oxygen supply and demand. As some authors suggest an average difference of $7 \pm 4 \%$ exists between both variables (18), there is larger difference especially in low cardiac output states (19). Consequently, trending of $\mathrm{ScvO}_{2}$ is probably more clinically relevant (18) and high values $(\geq 77.4 \%)$ should alert in terms of systemic inflammation, lactic acidosis, and increase in mortality (20).

Still, thermodilution techniques are regarded as clinical gold standard for the measurement of cardiac output in critically ill patients. Transpulmonary thermodilution has been shown to be equivalent in accuracy when compared to pulmonary artery thermodilution (21) which is often considered as clinical gold standard. Volumetric parameters (i.e., intrathoracic blood volume, global end-diastolic blood volume), which are assessed by the transpulmonary technique, are regarded superior to static parameters of cardiac preload, e.g., cardiac filling pressures (22). Treatment algorithms using transpulmonary indicator dilution have been described to be associated with a reduction in ICU stay, less organ dysfunction, and earlier ready for discharge from the ICU (21). Critically ill patients with subarachnoid hemorrhage, patients after major burn trauma or cardiac arrest were found to have more stable organ function when managed by transpulmonary thermodilution with integrated pulse contour analysis (21). So far, large randomized, controlled studies in the ICU using this system are missing. More recently, flow-directed protocols for intraoperative hemodynamic management using dynamic parameters of fluid responsiveness, i.e., PPV and SVV, have been found to significantly reduce perioperative complication rates, especially in patients undergoing major abdominal surgery $(23,24)$. To date, PPV is the most reliable predictor of fluid responsiveness in critically ill patients undergoing mechanical positive-pressure ventilation without cardiac arrhythmias (25). However, predictive properties of PPV with respect to fluid responsiveness may be even higher when considering amplitude of airway pressures (26). Future studies are warranted to show in how far integration of respiratory variables (possibly in an automated manner) will improve the predictive properties of PPV. Although in a lower extent, PPV may even be helpful for estimating fluid responsiveness in spontaneously breathing patients as long as no forced respiratory maneuvers occur (27).

Over the last few years, more systems based on uncalibrated pulse contour analysis for a beat-to-beat monitoring of cardiac output are emerging. On the first glance attractive due to the fact that peripheral (e.g., radial) arterial cannulation and without need for a reference method, data are conflicting and reliability of measuring absolute cardiac output correctly is still a matter of clinical studies (28-30). However, trending of cardiac output by an uncalibrated technique has been reported to be more reliable (31). Although intraoperative use of such systems has been found to reduce complication rates, further studies are mandatory to assess their accuracy (32) and potential benefit by implementing in the ICU.

One clinically increasingly attractive technique is the passive leg raising (PLR) maneuver while using a continuous monitoring system which allows real-time following of its effects (33). PLR is a test that predicts whether cardiac output will increase with volume expansion, i.e., around $300 \mathrm{~mL}$ of blood from the lower body to the heart. Since no external fluid is given, hemodynamic effects are rapidly reversible and there is no risk of fluid overload. However, several rules should be followed. First, PLR should start from the semi-recumbent and not the supine position as blood from the splanchnic region is mobilized by adding trunk lowering. Second, the PLR effects must be assessed by a direct measurement of cardiac output and not by the simple measurement of blood pressure. Furthermore, the cardiac output monitoring technique during PLR must be able to detect short-term and transient changes since the PLR effects may vanish quickly. For instance, arterial pulse contour analysis, echocardiography, esophageal Doppler, or contour analysis of the volume clamp-derived arterial pressure can be used. Fourth, cardiac output must be measured not only before and during PLR but also after PLR when the patient is back in the semi-recumbent position. As, pain, cough, discomfort, and awakening could provoke adrenergic stimulation, resulting in mistaken interpretation of cardiac output changes, PLR must be performed by adjusting the bed and not by manually raising the patient's legs.

One step further is the use of totally non-invasive techniques for continuous measurement of blood pressure and cardiac output in critically ill patients. Finger-cuffed systems (34-37) which by pulse contour analysis allow continuous monitoring of cardiac output or radial artery applanation for blood pressure measurement $(38,39)$ are currently evaluated in the ICU. Noteworthy, some of these systems use a reference (e.g., oscillometry). Although promising data could be obtained over the last years, their routine use in severely ill patients cannot be advocated at this moment.

As a classical Doppler principle-based technology, assessment of cardiac output by esophageal flow probe requires the velocitytime-integral and the vessel cross-sectional area (40). Thus by definition, the esophageal Doppler technique can merely obtain flow in the descending aorta and measurement of absolute cardiac output is not possible. Furthermore, assumption about the aortic size may be erroneous. Moreover, the system uses the peak velocity a surrogate of cardiac contractility and the corrected flow time, i.e., a dynamic estimate of preload. While earlier studies reported positive influence on length of stay or complications in patients undergoing colorectal surgery, newer trials did not show any benefit from such monitoring (41). Data in critically ill patients are rare and warrant further evaluation (42). Noteworthy, movements may affect the precision of readings derived from the esophageal 
Doppler. Another approach is a supra-sternal ultrasound probe using the flow profile of the ascending aorta. As mentioned above, two main sources may explain the inferiority to thermodilution techniques for measurement of cardiac output which are related to the Doppler measurement of aortic blood flow (i.e., the velocity time interval) and estimation of the aortic cross-sectional area which is derived from an algorithm based on patient size and has nothing to do with Doppler. Data suggest that this technique has the ability to track cardiac output over time properly, however, factors like patient age has significant impact on its accuracy (43).

Although transesophageal echocardiography is not a classical monitoring technique and normally applicable intermittently, a miniaturized $(5.5 \mathrm{~mm}$ diameter), disposable transesophageal echocardiography probe which may be kept in situ for up to $72 \mathrm{~h}$ has recently been introduced into the market. Although this method is gaining popularity as a continuous mode of echocardiographic assessment in critical care, it is clearly operator-dependent and needs further evaluation in anesthesia and intensive care (44).

A complete other approach are non-invasive Fick-principlebased techniques. For instance, transcutaneous assessment of soluble indicators (e.g., indocyanine green) has been suggested for measurement of cardiac output. In this technique, (peripheral) venous indicator injection and downstream concentration measurement (i.e., by a finger sensor) allow recording concentrationtime curves after adequate mathematical analysis cardiac output. However, the indicator concentration is obtained indirectly from optical densities and the relation between both has primarily been derived in healthy volunteers. Since absolute concentrations are mandatory for correct assessment of cardiac output and since physical properties of the skin and other tissues may significantly differ from healthy humans, data in critically ill patients were not convincing (45). Another Fick-principle-derived technique is the carbon dioxide rebreathing system. Introduced in 1999 (46), the system uses the differential Fick partial rebreathing technique to measure cardiac output in intubated and mechanically ventilated patients. Decreased correlation between this technique and pulmonary artery thermodilution has been reported in high cardiac output states, low minute ventilation, increased intrapulmonary shunt, and severe chest trauma (47). Besides these drawbacks, the system does not provide information on cardiac preload and, thus, its use particularly in critically ill patients cannot be recommended.

Both, bioreactance and bioimpedance are non-invasive methods for estimation of cardiac output. Known for many decades, thoracic bioimpedance allows continuous estimation of cardiac output based on the specific electric resistance of the thorax which changes during the cardiac cycle. A small current is transmitted between electrodes placed on the lower thorax and neck, and the

\section{References}

1. Swan HJ, Ganz W, Forrester J, Marcus H, Diamond G, Chonette D. Catheterization of the heart in man with use of a flow-directed balloon-tipped catheter. N Engl J Med (1970) 283:447-51. doi:10.1056/NEJM197008272830902

2. Connors AF Jr, Speroff T, Dawson NV, Thomas C, Harrell FE Jr, Wagner D, et al. The effectiveness of right heart catheterization in the initial care of critically ill patients. SUPPORT Investigators. JAMA (1996) 276:889-97. doi:10.1001/jama. 276.11 .889 voltage is measured. The electric impedance is derived from the voltage, and is inversely proportional to aortic blood flow. The accuracy of thoracic bioimpedance is affected by alterations in extravascular lung water, respiratory cycle-dependent alterations in venous blood flow, increased aortic stiffness, interference from the mechanical ventilator, and movement of the electrodes. Data on the validity of thoracic bioimpedance in relation to thermodilution estimation of cardiac output have been conflicting and refinements in this technique are required (48). A similar approach, electrical velocimetry $(49,50)$, is a bioimpedance method of $\mathrm{CO}$ determination measuring changes in transthoracic impedance during cardiac ejection to calculate stroke volume. The device is based on emission of a high-frequency $(50 \mathrm{kHz})$ and low-amperage $(2 \mathrm{~mA})$ alternating electrical current of constant amplitude via a pair of surface electrodes across the left side of the thorax. So far, inconsistent data in critically ill patients were reported $(51,52)$.

While the bioimpedance measures changes in amplitude, bioreactance relies on changes in signal frequency. Thoracic biorectance is more refined than thoracic bioimpedance as the ability to accurately measure phase shifts is less dependent on external noise and electrical interference. First data comparing thoracic biorectance to thermodilution techniques suggests that the methods are comparable $(53,54)$. However, adequate clinical studies are still required to validate the utility of bioreactance and bioimpedance in critically ill patients.

Last but not least, pulse oximetry as a fully non-invasive technique may be a helpful tool in assessing hemodynamics (55). In principle, plethysmographic waveform analysis requires specific tools and software that are not yet widely available. The plethysmographic variability index is based on perfusion index variations during the respiratory cycle and allows automated and continuous calculation of the respiratory variations in the pulse oxymeter waveform amplitude. Data from the operative setting were promising, however, the system is less reliable in critically ill patients and in about one-tenth of vasopressor-dependent patients no adequate signal quality could be obtained (56).

In conclusion, independently the methodological considerations and requirements to guarantee adequate accuracy, calibrated systems are still most reliable for the measurement of cardiac output in critically ill patients. However, the monitoring system per se is not outcome relevant but the underlying treatment algorithms are more important. Up to date, it seems indicated that with higher patients' morbidity application of non-invasive techniques should be held restrictive (57). While without any doubt existing monitoring devices will be refined and new techniques developed, the future will show which treatment strategy does match the best requirements to improve outcome of critically ill patients.

3. Richard C, Warszawski J, Anguel N, Deye N, Combes A, Barnoud D, et al. Early use of the pulmonary artery catheter and outcomes in patients with shock and acute respiratory distress syndrome: a randomized controlled trial. JAMA (2003) 290:2713-20. doi:10.1001/jama.290.20.2713

4. Sandham JD, Hull RD, Brant RF, Knox L, Pineo GF, Doig CJ, et al. A randomized, controlled trial of the use of pulmonary-artery catheters in high-risk surgical patients. N Engl J Med (2003) 348:5-14. doi:10.1056/NEJMoa021108

5. Harvey S, Harrison DA, Singer M, Ashcroft J, Jones CM, Elbourne D, et al. Assessment of the clinical effectiveness of pulmonary artery catheters in 
management of patients in intensive care (PAC-Man): a randomised controlled trial. Lancet (2005) 366:472-7. doi:10.1016/S0140-6736(05)67061-4

6. Clinical Trials Network; Wheeler AP, Bernard GR, Thompson BT, Schoenfeld D, Wiedemann HP, et al. Pulmonary-artery versus central venous catheter to guide treatment of acute lung injury. National Heart, Lung, and Blood Institute Acute Respiratory Distress Syndrome (ARDS). N Engl J Med (2006) 354:2213-24. doi:10.1056/NEJMoa061895

7. Vincent JL, Pinsky MR, Sprung CL, Levy M, Marini JJ, Payen D, et al. The pulmonary artery catheter: in medio virtus. Crit Care Med (2008) 36:3093-6. doi:10.1097/CCM.0b013e31818c10c7

8. Gershengorn HB, Wunsch H. Understanding changes in established practice: pulmonary artery catheter use in critically ill patients. Crit Care Med (2013) 41:2667-76. doi:10.1097/CCM.0b013e318298a41e

9. Cecconi M, De Backer D, Antonelli M, Beale R, Bakker J, Hofer C, et al. Consensus on circulatory shock and hemodynamic monitoring. Task force of the European Society of Intensive Care Medicine. Intensive Care Med (1014) 40:1795-815. doi:10.1007/s00134-014-3525-z

10. Ospina-Tascon GA, Cordioli RL, Vincent JL. What type of monitoring has been shown to improve outcomes in acutely ill patients? Intensive Care Med (2008) 34:800-20. doi:10.1007/s00134-007-0967-6

11. Hamilton MA, Cecconi M, Rhodes A. A systematic review and meta-analysis on the use of preemptive haemodynamic intervention to improve postoperative outcomes in moderate and high-risk surgical patients. Anesth Analg (2011) 112:1392-402. doi:10.1213/ANE.0b013e3181eeaae5

12. Cecconi M, Corredor C, Arulkumaran N, Abuella G, Ball J, Grounds RM, et al. Clinical review: goal-directed therapy-what is the evidence in surgical patients? The effect on different risk groups. Crit Care (2013) 17:209. doi:10. $1186 / \mathrm{cc} 11823$

13. Cecconi M, Arulkumaran J, Kilic J, Ebm C, Rhodes A. Update on hemodynamic monitoring and management in septic patients. Minerva Anestesiol (2014) 80:701-11.

14. Siegenthaler N, Giraud R, Saxer T, Courvoisier DS, Romand JA, Bendjelid K. Haemodynamic monitoring in the intensive care unit: results from a web-based Swiss survey. Biomed Res Int (2014) 2014:129593. doi:10.1155/2014/129593

15. Srinivasa S, Kahokehr A, Soop M, Taylor M, Hill AG. Goal-directed fluid therapy - a survey of anaesthetists in the UK, USA, Australia and New Zealand. BMC Anesthesiol (2013) 13:5. doi:10.1186/1471-2253-13-5

16. Rivers E, Nguyen B, Havstad S, Ressler J, Muzzin A, Knoblich B, et al. Early goal-directed therapy in the treatment of severe sepsis and septic shock. N Engl J Med (2001) 345:1368-77. doi:10.1056/NEJMoa010307

17. ProCESS Investigators; Yealy DM, Kellum JA, Huang DT, Barnato AE, Weissfeld LA, et al. A randomized trial of protocol-based care for early septic shock. NEngl J Med (2014) 370:1683-93. doi:10.1056/NEJMoa1401602

18. Reinhart K, Kuhn HJ, Hartog C, Bredle DL. Continuous central venous and pulmonary artery oxygen saturation monitoring in the critically ill. Intensive Care Med (2004) 30:1572-8. doi:10.1007/s00134-004-2337-y

19. Varpula M, Karlsson S, Ruokonen E, Pettilä V. Mixed venous oxygen saturation cannot be estimated by central venous oxygen saturation in septic shock. Intensive Care Med (2006) 32:1336-43. doi:10.1007/s00134-006-0270-y

20. Perz S, Uhlig T, Kohl M, Bredle DL, Reinhart K, Bauer M, et al. Low and "supranormal" central venous oxygen saturation and markers of tissue hypoxia in cardiac surgery patients: a prospective observational study. Intensive Care Med (2011) 37:52-9. doi:10.1007/s00134-010-1980-8

21. Sakka SG, Reuter DA, Perel A. The transpulmonary thermodilution technique. J Clin Monit Comput (2012) 26:347-53. doi:10.1007/s10877-012-9378-5

22. Huber W, Umgelter A, Reindl W, Franzen M, Schmidt C, von Delius S, et al. Volume assessment in patients with necrotizing pancreatitis: a comparison of intrathoracic blood volume index, central venous pressure, and hematocrit, and their correlation to cardiac index and extravascular lung water index. Crit Care Med (2008) 36:2348-54. doi:10.1097/CCM.0b013e3181809928

23. Salzwedel C, Puig J, Carstens A, Bein B, Molnar Z, Kiss K, et al. Perioperative goal-directed haemodynamic therapy based on radial arterial pulse pressure variation and continuous cardiac index trending reduces postoperative complications after major abdominal surgery: a multi-center, prospective, randomized study. Crit Care (2013) 17:R191. doi:10.1186/cc12885

24. Benes J, Giglio M, Brienza N, Michard F. The effects of goal-directed fluid therapy based on dynamic parameters on post-surgical outcome: a metaanalysis of randomized controlled trials. Crit Care (2014) 18:584. doi:10.1186/ s13054-014-0584-z
25. Marik PE, Cavallazzi R, Vasu T, Hirani A. Dynamic changes in arterial waveform derived variables and fluid responsiveness in mechanically ventilated patients: a systematic review of the literature. Crit Care Med (2009) 37:2642-7. doi:10.1097/CCM.0b013e3181a590da

26. Vallée F, Richard JC, Mari A, Gallas T, Arsac E, Verlaan PS, et al. Pulse pressure variations adjusted by alveolar driving pressure to assess fluid responsiveness. Intensive Care Med (2009) 35:1004-10. doi:10.1007/s00134-009-1478-4

27. Soubrier S, Saulnier F, Hubert H, Delour P, Lenci H, Onimus T, et al. Can dynamic indicators help the prediction of fluid responsiveness in spontaneously breathing critically ill patients? Intensive Care Med (2007) 33:1117-24. doi:10. 1007/s00134-007-0644-9

28. Compton FD, Zukunft B, Hoffmann C, Zidek W, Schaefer JH. Performance of a minimally invasive uncalibrated cardiac output monitoring system (Flotrac/Vigileo) in haemodynamically unstable patients. Br J Anaesth (2008) 100:451-6. doi:10.1093/bja/aem409

29. Sakka SG, Kozieras J, Thuemer O, van Hout N. Measurement of cardiac output: a comparison between transpulmonary thermodilution and uncalibrated pulse contour analysis. Br J Anaesth (2007) 99:337-42. doi:10.1093/bja/aem177

30. Smetkin AA, Hussain A, Kuzkov VV, Bjertnæs LJ, Kirov MY. Validation of cardiac output monitoring based on uncalibrated pulse contour analysis vs transpulmonary thermodilution during off-pump coronary artery bypass grafting. Br J Anaesth (2014) 112:1024-31. doi:10.1093/bja/aet489

31. Petzoldt M, Riedel C, Braeunig J, Haas S, Goepfert MS, Treede H, et al. Stroke volume determination using transcardiopulmonary thermodilution and arterial pulse contour analysis in severe aortic valve disease. Intensive Care Med (2013) 39:601-11. doi:10.1007/s00134-012-2786-7

32. Paarmann H, Groesdonk HV, Sedemund-Adib B, Hanke T, Heinze H, Heringlake $\mathrm{M}$, et al. Lack of agreement between pulmonary arterial thermodilution cardiac output and the pressure recording analytical method in postoperative cardiac surgery patients. Br J Anaesth (2011) 106:475-81. doi:10.1093/bja/ aeq372

33. Monnet X, Teboul JL. Passive leg raising: five rules, not a drop of fluid! Crit Care (2015) 19:18. doi:10.1186/s13054-014-0708-5

34. Monnet X, Picard F, Lidzborski E, Mesnil M, Duranteau J, Richard C, et al. The estimation of cardiac output by the Nexfin device is of poor reliability for tracking the effects of a fluid challenge. Crit Care (2012) 16:R212. doi:10.1186/ cc11846

35. Martina JR, Westerhof BE, van Goudoever J, de Beaumont EM, Truijen J, Kim YS, et al. Noninvasive continuous arterial blood pressure monitoring with Nexfin(R). Anesthesiology (2012) 116:1092-103. doi:10.1097/ALN. ob013e31824f94ed

36. Vos JJ, Poterman M, Mooyaart EA, Weening M, Struys MM, Scheeren TW, et al. Comparison of continuous noninvasive finger blood pressure monitoring with conventional intermittent automated arm blood pressure measurement in patients under general anaesthesia. Br J Anaesth (2014) 113:67-74. doi:10.1093/ bja/aeu091

37. Hohn A, Defosse JM, Becker S, Steffen C, Wappler F, Sakka SG. Non-invasive continuous arterial pressure monitoring with Nexfin does not sufficiently replace invasive measurements in critically ill patients. Br J Anaesth (2013) 111:178-84. doi:10.1093/bja/aet023

38. Compton F, Wittrock M, Schaefer JH, Zidek W, Tepel M, Scholze A. Noninvasive cardiac output determination using applanation tonometry-derived radial artery pulse contour analysis in critically ill patients. Anesth Analg (2008) 106:171-4. doi:10.1213/01.ane.0000297440.52059.2c

39. Meidert AS, Huber W, Müller JN, Schöfthaler M, Hapfelmeier A, Langwieser N, et al. Radial artery applanation tonometry for continuous non-invasive arterial pressure monitoring in intensive care unit patients: comparison with invasively assessed radial arterial pressure. Br J Anaesth (2014) 112:521-8. doi:10.1093/ bja/aet 400

40. Gan TJ, Soppitt A, Maroof M, el-Moalem H, Robertson KM, Moretti E, et al. Goal-directed intraoperative fluid administration reduces length of hospital stay after major surgery. Anesthesiology (2002) 97:820-6. doi:10.1097/ 00000542-200210000-00012

41. Srinivasa S, Lemanu DP, Singh PP, Taylor MH, Hill AG. Systematic review and meta-analysis of oesophageal Doppler-guided fluid management in colorectal surgery. Br J Surg (2013) 100:1701-8. doi:10.1002/bjs.9294

42. Dark PM, Singer M. The validity of trans-esophageal Doppler ultrasonography as a measure of cardiac output in critically ill adults. Intensive Care Med (2004) 30:2060-6. doi:10.1007/s00134-004-2430-2 
43. Huang L, Critchley LA. Accuracy and precision of the USCOM: does a metaanalysis provide the answer? Anaesthesia (2013) 68:431-2. doi:10.1111/anae. 12199

44. Cioccari L, Baur HR, Berger D, Wiegand J, Takala J, Merz TM. Hemodynamic assessment of critically ill patients using a miniaturized transesophageal echocardiography probe. Crit Care (2013) 17:R121. doi:10.1186/cc12793

45. Sakka SG, Reinhart K, Wegscheider K, Meier-Hellmann A. Comparison of cardiac output and circulatory blood volumes by transpulmonary thermo-dye dilution and transcutaneous indocyanine green measurement in critically ill patients. Chest (2002) 121:559-65. doi:10.1378/chest.121.2.559

46. Kotake Y, Moriyama K, Innami Y, Shimizu H, Ueda T, Morisaki H, et al. Performance of noninvasive partial $\mathrm{CO}_{2}$ rebreathing cardiac output and continuous thermodilution cardiac output in patients undergoing aortic reconstruction surgery. Anesthesiology (2003) 99:283-8. doi:10.1097/ 00000542-200308000-00009

47. Funk DJ, Moretti EW, Gan TJ. Minimally invasive cardiac output monitoring in the perioperative setting. Anesth Analg (2009) 108:887-97. doi:10.1213/ane. 0b013e31818ffd99

48. Raaijmakers E, Faes TJ, Scholten RJ, Goovaerts HG, Heethaar RM. A metaanalysis of three decades of validating thoracic impedance cardiography. Crit Care Med (1999) 27:1203-13. doi:10.1097/00003246-199906000-00053

49. Schmidt C, Theilmeier G, Van Aken H, Korsmeier P, Wirtz SP, Berendes E, et al. Comparison of electrical velocimetry and transoesophageal Doppler echocardiography for measuring stroke volume and cardiac output. Br J Anaesth (2005) 95:603-10. doi:10.1093/bja/aei224

50. Keren H, Burkhoff D, Squara P. Evaluation of a noninvasive continuous cardiac output monitoring system based on thoracic bioreactance. Am J Physiol Heart Circ Physiol (2007) 293:H583-9. doi:10.1152/ajpheart.00195.2007

51. Zoremba N, Bickenbach J, Krauss B, Rossaint R, Kuhlen R, Schälte G. Comparison of electrical velocimetry and thermodilution techniques for the measurement of cardiac output. Acta Anaesthesiol Scand (2007) 51:1314-9. doi:10.1111/ j.1399-6576.2007.01445.x
52. Heringlake M, Handke U, Hanke T, Eberhardt F, Schumacher J, Gehring H, et al. Lack of agreement between thermodilution and electrical velocimetry cardiac output measurements. Intensive Care Med (2007) 33:2168-72. doi:10. 1007/s00134-007-0828-3

53. Squara P, Denjean D, Estagnasie P, Brusset A, Dib JC, Dubois C. Noninvasive cardiac output monitoring (NICOM): a clinical validation. Intensive Care Med (2007) 33:1191-4. doi:10.1007/s00134-007-0640-0

54. Kupersztych-Hagege E, Teboul JL, Artigas A, Talbot A, Sabatier C, Richard C, et al. Bioreactance is not reliable for estimating cardiac output and the effects of passive leg raising in critically ill patients. Br J Anaesth (2013) 111:961-6. doi:10.1093/bja/aet282

55. Cannesson M, Attof Y, Rosamel P, Desebbe O, Joseph P, Metton O, et al. Respiratory variations in pulse oximetry plethysmographic waveform amplitude to predict fluid responsiveness in the operating room. Anesthesiology (2007) 106:1105-11. doi:10.1097/01.anes.0000267593.72744.20

56. Loupec T, Nanadoumgar H, Frasca D, Petitpas F, Laksiri L, Baudouin D, et al. Pleth variability index predicts fluid responsiveness in critically ill patients. Crit Care Med (2011) 39:294-9. doi:10.1097/CCM.0b013e3181ffdelc

57. Cannesson M, Manach YL. Noninvasive hemodynamic monitoring: no high heels on the farm; no clogs to the opera. Anesthesiology (2012) 117:937-9. doi:10.1097/ALN.0b013e3182700ad6

Conflict of Interest Statement: Samir G. Sakka is a member of the Medical Advisory Board of PULSION Medical Systems SE, Feldkirchen, Germany.

Copyright (C) 2015 Sakka. This is an open-access article distributed under the terms of the Creative Commons Attribution License (CC BY). The use, distribution or reproduction in other forums is permitted, provided the original author(s) or licensor are credited and that the original publication in this journal is cited, in accordance with accepted academic practice. No use, distribution or reproduction is permitted which does not comply with these terms. 